\title{
PyroSim-Based Numerical Simulation of Fire Safety and Evacuation Behaviour of College Buildings
}

\author{
Mingbiao $\mathrm{Xu}^{*}$, Dehong Peng \\ School of Construction Engineering, Yiwu Industrial \& Commercial College, Yiwu 322000, China
}

Corresponding Author Email: mingbiaoxu@163.com

https://doi.org/10.18280/ijsse.100218

Received: 10 October 2019

Accepted: 17 January 2020

\section{Keywords:}

college buildings, fire dynamics, evacuation simulation, Pyrosim, pathfinder

\begin{abstract}
In colleges, fire accident poses a severe threat to the lives and properties of teachers and students, because fire evacuation is difficult due to the dense population, numerous experimental instruments, and various flammables and explosives on campus. This paper explores deep into the fire safety of college buildings, and analyses the types and hazard sources of fire on campus. Then, a building information model (BIM) was established according to the location of fire source, the type of fire growth, and the maximum heat release rate, and applied to fire process simulation on PyroSim and Pathfinder. The simulation results show that the smoke at staircases 1 and 2 on the second floor reached the critical height at $63 \mathrm{~s}$ and $76 \mathrm{~s}$, respectively; despite a relatively long distance from the fire classroom, the smoke at staircase 3 on the second floor reached the critical height at $123 \mathrm{~s}$, making the staircase impassable. Among the four evacuation exits, exit I suffered the greatest from the fire, and became impassable since 86s. The other exits and stairways on the first floor were affected but still passable. Except the fire classroom. The average temperature variation on the second floor was $5^{\circ} \mathrm{C}$. After the fire broke out, the total evacuation time increased by $21 \mathrm{~s}$. Exit I is the only evacuation exit where the evacuation is faster under fire than under no fire. The research results provide a good reference for fire analysis and fire protection of other buildings.
\end{abstract}

\section{INTRODUCTION}

According to data from the World Fire Statistics Centre (WFSC), more than 7 million fires occur annually worldwide [1-3]. With a vast territory and large population, China is one of the countries with frequent fires. In recent years, college administrators are increasingly troubled by hidden fire hazards in college buildings and the fire safety of campus. Over the past decade, more than 4,000 fire accidents occurred in colleges across China, mostly in classrooms and labs. These accidents killed more than 50 teachers and students, causing over RMB 25 billion yuan of cumulative economic losses.

The main reason for these accidents lies in the expansion of enrolment in the new era, and the marketization of logistics departments. In particular, the proliferation of electronic products (e.g. cell phones and computers) increases the load on the grid of college buildings. The surging power consumption has amplified the hidden fire hazards. Moreover, the fire safety of college buildings faces severe challenges from the following factors: the poor fire resistance of many old buildings, the diversity of experimental instruments and reagents, as well as the high density and complexity of the population on campus. To ensure the fire safety of college buildings, it is very meaningful to numerically simulate the smoke layer height, indoor fire temperature, and smoke diffusion law, evaluate the evacuation time, and make dynamic adjustment to evacuation route.

Numerical simulation of fire has long been a research hotspot among scholars at home and abroad [4-8]. Four decades ago, scholars in some developed countries began to systematically explore fire safety design based on building performance. With the development of numerical simulation, more than 20 calculation software have emerged for fire simulation and evacuation modelling, including PyroSim, Pathfinder, STEP, and Analog. Among them, PyroSim is an excellent fire dynamics simulator (FDS) software developed by the National Institute of Standards and Technology (NIST). The software has been widely applied to simulate various fire processes and evacuation scenarios [9, 10], making fire research more convenient and intuitive. To study fire evacuation, the NIST also designed the Pathfinder software to simulate personnel movement. Pathfinder simulations can produce many important results.

Numerical simulation can realize many experiments that are too large to be implemented, such as traffic tunnel fires [1113], and high-altitude aircraft fires [14]. Through PyroSim numerical simulation, Liang et al. [15] investigated the effects of different fire points on the degree of fire hazard on highspeed trains, revealing that vehicle integration is the main fireproof defect of high-speed trains. Chen et al. [16] studied the relationship between emergency exits and the number of evacuees. Fang et al. [17] explored the influence of staircase design on building evacuation based on Pathfinder numerical simulation. With the aid of spatial grid evacuation model, Fang et al. [18] examined the relationship between evacuation speed and crowd density. Glasa et al. [19] established an FDS-based cinema fire model; the simulation results show that the most dangerous places in the cinema hall are at the rear and the left side, and the curved ceiling is even more dangerous for the audience. Huo et al. [20] simulated fire evacuation in high- 
rises, suggesting that personal risk perception and emotional state will be greatly affected by real fires. Chi et al. [21] reconstructed the hidden fire hazard and evacuation plan of a hotel through FDS and EVAC programs, and put forward new suggestions on fire safety. Based on PyroSim, Long et al. [22] analysed the temperature, visibility, smoke height, heat flow, and smoke movement of all doors and windows of a dormitory building, and compared the results with the situation of the original fire room with closed windows. Rahouti et al. [23] investigated fire safety in high-rise dormitories through fireand agent-based modelling approaches.

In recent years, fire science has become more and more mature. Currently, the relevant research covers transport, open field, factories, hospitals, malls, and many other public places. However, the numerical simulation of fire remains in the development stage, failing to catch up with the pace of social development. This calls for in-depth research on the new features of fire safety, namely, the college buildings in the context of educational reform and technological progress.

Focusing on indoor fire of college buildings, this paper analyses the safety of college buildings, and explores the source of fire hazards in colleges. Then, a simulation model was constructed based on PyroSim and Pathfinder, according to the location of fire source, the type of fire growth, and the maximum heat release rate. The established model was adopted to simulate the fire process and the evaluation in college buildings. The change laws of temperature and visibility in fire were obtained through numerical simulation. Finally, the evacuation behaviour was simulated in the light of fire and smoke concentration.

The remainder of this paper is organized as follows: Section 2 introduces the preliminary knowledge of our research; Section 3 examines the fire safety of college buildings; Section 4 constructs the simulation model for fires in college buildings; Section 5 analyses the simulation results; Section 6 puts forward conclusions.

\section{PRELIMINARIES}

To simulate fire dynamics, it is necessary to establish the thermally driven Navier-Stokes (NS) equations of the system, and solve the thermodynamic response by corresponding numerical methods. The common solving methods include direct numerical simulation (DNS) and large eddy simulation (LES).

The DNS sets up models based on time and spatial scales, without needing an additional turbulence model. However, a huge computing load will be incurred by directly solving turbulence control equations. As a result, the DNS only applies to laminar flow or turbulent flow with a low Reynolds coefficient. By contrast, the LES divides the instantaneous turbulent motions into large-scale and small-scale motions for calculation and simulation, which greatly reduces the computing load. PyroSim is a professional numerical simulation software for computational fluid dynamics (CFD) based on the LES.

The constitutive equations necessary to model the fluid temperature field, concentration field, and other fluid dynamics in college buildings are as follows:

(1) Continuity equation:

$$
\frac{\partial \rho}{\partial t}+\nabla \cdot \rho \vec{u}=0
$$

where, $\vec{u}$ is the velocity vector; $\rho$ is the density; $\mathrm{t}$ is the time.

(2) Ideal gas state equation:

$$
P=\frac{\rho R T}{M}
$$

where, $M$ is the molecular mass of mixed gas; $R$ is the ideal gas constant.

(3) Momentum conservation equation:

$$
\rho\left(\frac{\partial \vec{u}}{\partial t}+(\vec{u} \cdot \nabla) \vec{u}\right)+\nabla p=\rho g+\vec{f}+\nabla \cdot \tau
$$

where, $\mathrm{g}$ is the acceleration of gravity; $\vec{f}$ is the surface force acting on the fluid.

(4) Components conservation equation:

$$
\frac{\partial}{\partial t}\left(\rho Y_{i u}^{r}\right)=\nabla \cdot\left(\rho D_{i} \nabla Y_{i}\right)+\dot{m}_{i}^{m}
$$

where, $D_{i}$ and $Y_{i}$ are the diffusion coefficient and mass fraction of the i-th component, respectively; $\dot{m}_{i}^{m}$ is the mass production rate of the $i$-th component in unit volume.

(5) Energy equation:

$$
\begin{aligned}
& \frac{\partial}{\partial t}\left(\rho h_{u}^{r}\right)+\nabla \cdot(\rho h)=\frac{\partial p}{\partial t}^{r} \cdot \nabla p-\cdot \nabla(k \nabla T) \\
& +\sum_{i} \nabla\left(h_{i} \rho D_{i} \nabla Y_{i}\right)
\end{aligned}
$$

where, $h$ is specific enthalpy; $k$ is thermal conductivity.

\section{FIRE SAFETY OF COLLEGE BUILDINGS}

At present, fires occasionally occur in colleges of China, and sometimes cause serious consequences. According to Provisions on the Administration of Fire Control Safety of State Organs, Organizations, Enterprises and Institutions, colleges with $>100$ student beds and college libraries are key units of fire safety. Many local laws and regulations have been issued to ensure the fire safety of colleges. These legal documents demand high attention to key fire safety units like colleges.

Currently, there are more than 2,000 colleges across China. Most colleges have numerous experimental instruments, and dense and complex population on campus. The college buildings tend to be tall, energy-consuming, and thronged with combustibles. Many people cluster together in most college activities. In general, the colleges in China have a high density of buildings, assets, and personnel. In the event of a fire, the escape time is very limited for the large population on campus, posing a serious threat to the lives and properties of teachers and students. The fire will also damage the expensive precision instruments, causing heavy economic losses and impeding scientific research.

Fire is a combustion phenomenon that seriously threatens the safety of personnel, property, and environment. The Chinese Ministry of Public Security divides fire into 4 classes (Table 1), while Chinese national standard (GB/T4968) divides fire into 6 categories (Table 2). 
Table 1. Fire classes defined by the Chinese Ministry of Public Security

\begin{tabular}{cccc}
\hline Fire class & $\begin{array}{c}\text { Number of deaths } \\
\mathbf{m} / \mathbf{p e r s o n}\end{array}$ & $\begin{array}{c}\text { Number of serious injuries } \\
\mathbf{h} / \text { persons }\end{array}$ & $\begin{array}{c}\text { Direct property loss } \\
\mathbf{p} / \mathbf{R M B} \text { million yuan }\end{array}$ \\
\hline General fire & $\mathrm{m}<3$ & $\mathrm{~h}<10$ & $\mathrm{p}<10$ \\
Large fire & $3 \leq \mathrm{m}<10$ & $10 \leq \mathrm{h}<50$ & $10 \leq \mathrm{p}<50$ \\
Major fire & $10 \leq \mathrm{m}<30$ & $50 \leq \mathrm{h}<100$ & $50 \leq \mathrm{p}<100$ \\
Extraordinarily serious fire & $30 \leq \mathrm{m}$ & $100 \leq \mathrm{h}$ & $100 \leq \mathrm{p}$ \\
\hline
\end{tabular}

Table 2. Fire categories defined by Chinese national standard

\begin{tabular}{cc}
\hline Fire category & Combustible type and combustion features \\
\hline Category A & Solid fire \\
Category B & Liquid or soluble solid fire \\
Category C & Gas fire \\
Category D & Metal fire \\
Category E & Electrical fire \\
Category F & Cookware fire \\
\hline
\end{tabular}

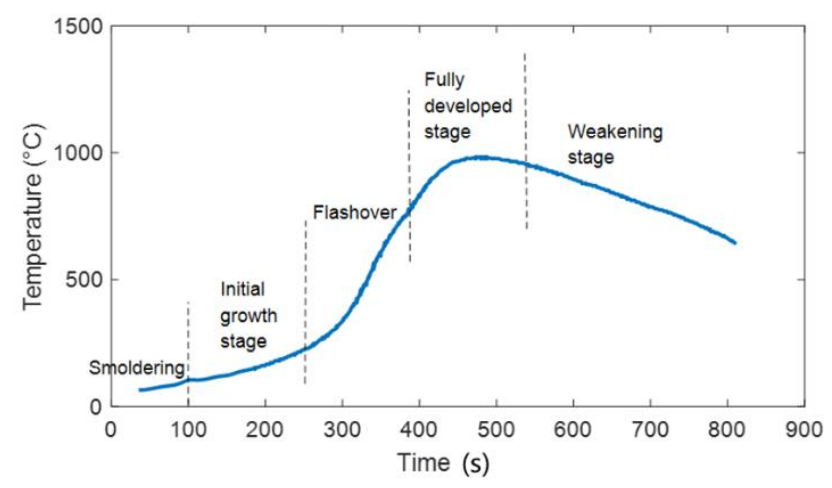

Figure 1. Temperature-time curve of indoor fire process

According to the relationship between temperature and time (Figure 1), the indoor fire process can be split into initial stage, fully developed stage, and weakening stage. In the initial stage, the combustion is limited to a small scope, and the mean indoor temperature is low. This is the best time to put out the fire. The fully developed stage is featured by intense combustion and rapid spread of fire, accompanied by flashover; the indoor temperature could reach $1,000^{\circ} \mathrm{C}$. The weakening stage begins once the mean indoor temperature drops to $80 \%$ of the peak indoor temperature. In this stage, there are relatively few combustibles, and a falling indoor temperature. The fire ends when the indoor temperature equals the outdoor temperature.

With dense population, college buildings are prone to fire accidents. The root causes and hidden hazards of fire must be identified for these buildings. According to hazards of fire sources and actual surveys, the fire sources of college buildings are summarized as follows:

(1) Improper design, installation, use, and maintenance of electrical devices:

In college buildings, there are many hidden hazards concerning electrical devices, e.g. overload, poor contact, short-circuiting, and improper use. For example, high-power light bulbs are often installed near combustibles (e.g. wooden boards and paper), failing to provide sufficient safe distance. In college libraries, the lamps are often too close to books, which may catch fire after being irradiated by the lamps for a long time. In addition, non-explosion-proof motors, lamps, and switches are sometimes used in flammable and explosive workshops.

(2) Lab chemicals:
There are many flammables and explosives in chemistry labs. Chemical reagents like benzenes, amines, alcohols, and ethers are potential fire sources. The solid substances in biology labs, namely, white phosphorus, yellow phosphorus, and titanium trichloride, may also cause fires. In mechanical labs, acetylene gas, liquefied petroleum gas, hydrogen, and oxygen, all of which are commonly used in welding, are combustible gases.

(3) Inadvertent use of fire and electricity for living and production:

Indoor fire might break out due to the illegal use of electrical appliances in dormitory, such as high-power heater, hair dryer, electric cup, and electric blanket. The inadvertent use of fire for living includes smoking, fire use in canteens, lighting, and setting off fireworks and firecrackers. The inadvertent use of fire for production include asphalt melting, boiling, and other operations whose temperature might surpass the ignition point of the object materials.

(4) Other flammables:

The other flammables in college buildings include books in the library, the materials in the archive room, the bills in the financial office, and the clothes in locker rooms and laundry rooms.

\section{SIMULATION MODELLING}

The fire scene to be simulated is illustrated in Figure 2, where 0 is the standard position of flame, i.e. the fireground, 1-3 are the serial number of staircases, and I-III are the serial number of exits. The classroom lies between staircases 1 and 2 , and close to evacuation exit I. In the event of a fire, the smoke could spread in both vertical and horizontal directions. Thus, all the students in the building must be evacuated.

Covering an area of $6,380 \mathrm{~m}^{2}$, the two-storey teaching building has 3 staircases and 4 evacuation exits. On the first floor, there are 2 teacher offices and 8 classrooms; on the second floor, there are 2 teacher offices and 12 classrooms. As mentioned above, the simulated fire breaks out in a classroom on the second floor.

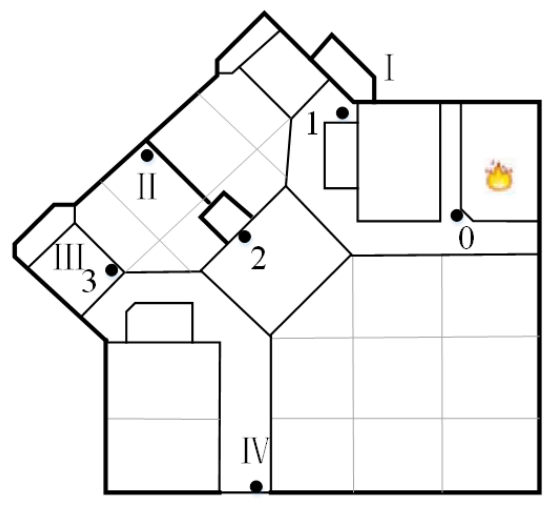

Figure 2. The plan of the second floor 


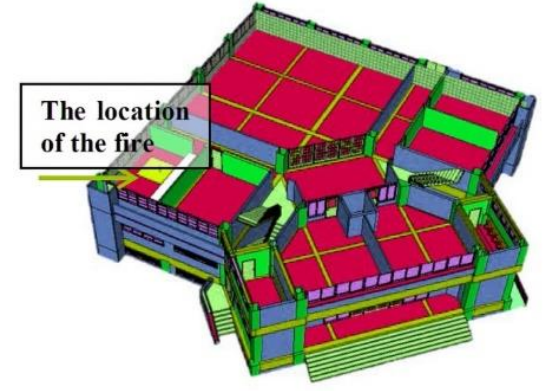

Figure 3. The location of the fire in PyroSim
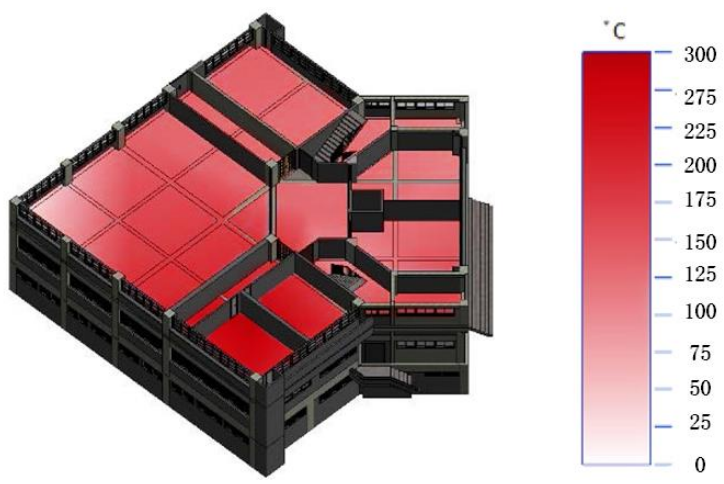

Figure 4. Simulated temperature
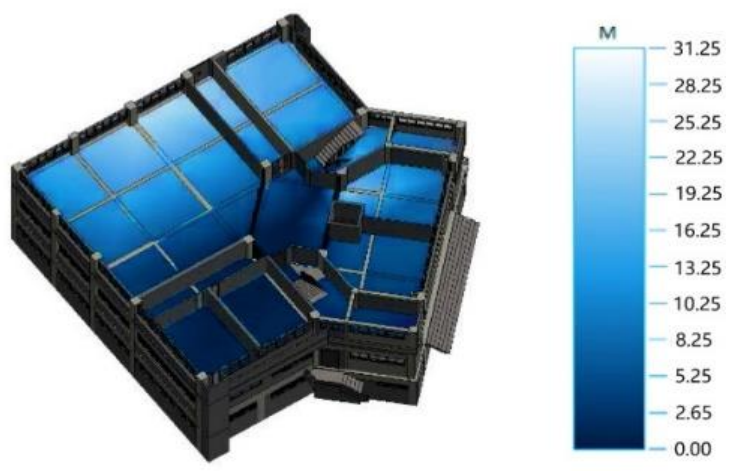

Figure 5. Simulated visibility

The building information model (BIM) of the teaching building was imported to PyroSim for modelling, and the ignition point was set as shown in Figure 3. The basic parameters and grids for fire simulation were configured in the software.

PyroSim can visually simulate various parameters of fire. For instance, the temperature around the fire ground can be visualized based on the simulated data on the user-specified floor and area in the database (Figure 4); the visibility in smoke can also be visualized (Figure 5).

\section{SIMULATION RESULTS AND ANALYSIS}

To capture the changes of fire in the teaching building, 11 smoke detectors and 4 thermocouples were deployed in the building. The smoke detectors were arranged at the ignition point 0 , and staircases 1-3 on the second floor, staircases 1,2 and 3 on the first floor, and the four evacuation exits. The thermocouples were placed at the ignition point 0 , and staircases 1-3 on the second floor. In subsequent figures, the first and second floors are denoted as $\mathrm{f} 1$ and $\mathrm{f} 2$, respectively; smoke detector is denoted as SD; thermocouple is denoted as THCP; staircase and evacuation exit are shortened as stairs and export, respectively.

In the early phase of combustion, lots of smoke is released due to smouldering. The smoke contains a huge amount of toxic gases and tiny particles, which may suffocate or poison the trapped personnel. The particles in the smoke reduce the passing rate of light, adding to the difficulty of escape and rescue. Hence, it is of great importance to study the smoke in fire. With the elapse of time, the smoke thickens as the fire grows stronger. Then, the visibility of the evacuation route will gradually reduce. Once the visibility drops to a threshold, the route will no longer be passable. The critical smoke height $H_{c}$ [24] can be expressed as:

$$
H_{s}<H_{c}=H_{P}+0.1 H_{b}
$$

where, $H_{p}$ is the typical height of human eyes; $H_{b}$ is the floor height.

The average height of male and female subjects in our research is $1.52 \mathrm{~m}$. The $H_{p}$ value is 0.8 times the average height, because the subjects will move with body bending forward during the fire. Since the net storey height is $3.5 \mathrm{~m}$, the critical smoke height $H_{c}$ can be obtained as 1.566 , i.e. $H_{c}<$ 1.566. The $H_{c}$ value was adopted to determine the closing time of each route. Based on the data captured by smoke detectors, a route will be close to all personnel, once the smoke height reaches the critical height.

Staircase 1 is the closest to the fire classroom, and was the first and most seriously affected place. As shown in Figure 6, both floors were greatly impacted by fire. Staircase 1 on the second floor was affected from $12 \mathrm{~s}$, where the smoke reached the critical height at $63 \mathrm{~s}$; from then on, this part of the staircase was closed. Staircase 1 on the first floor was affected from $21 \mathrm{~s}$, where the smoke reached the critical height at $88 \mathrm{~s}$; from then on, this part of the staircase was closed.

Staircase 2 is the second closest staircase to the fire classroom, and was also seriously affected. As shown in Figure 7, Staircase 2 on the second floor was affected from 23s, where the smoke reached the critical height at $76 \mathrm{~s}$; from then on, this part of the staircase was closed. Staircase 2 on the first floor was affected from 50s, but the rising smoke did not reach the critical height; thus, this part of the staircase was still passable.

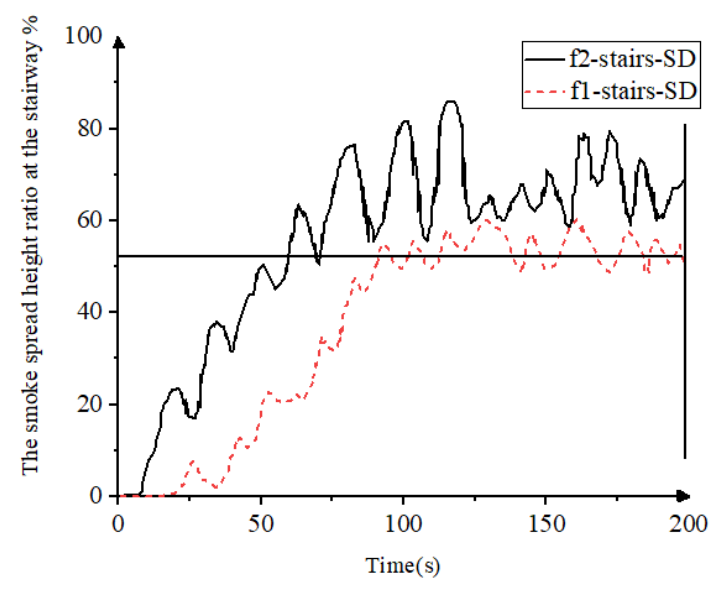

Figure 6. Smoke height at Staircase 1 


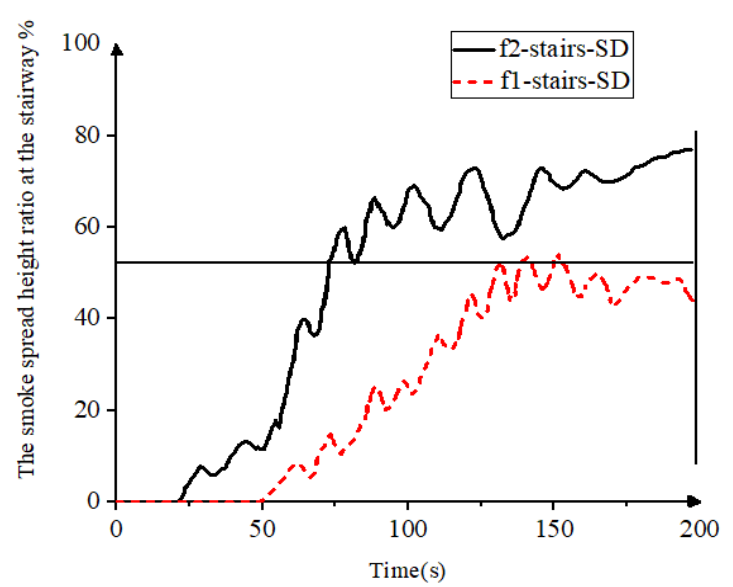

Figure 7. Smoke height at Staircase 2

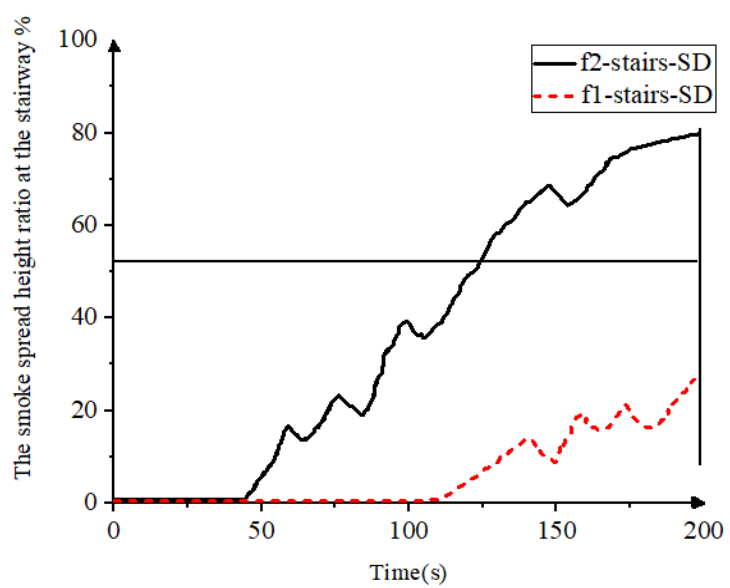

Figure 8. Smoke height at Staircase 3

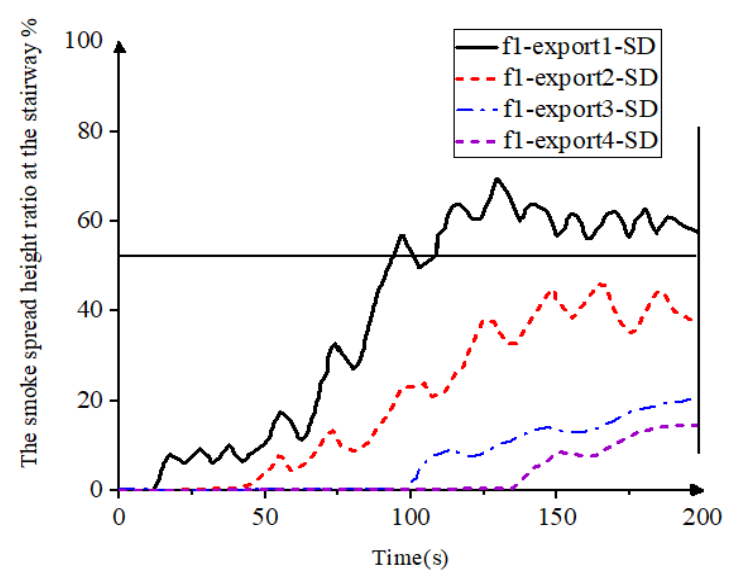

Figure 9. Smoke height at each evacuation exit on the first floor

Staircase 3 is the farthest staircase from the fire classroom, and was relatively slightly affected. As shown in Figure 8, Staircase 3 on the second floor was affected from $45 \mathrm{~s}$, where the smoke reached the critical height at $123 \mathrm{~s}$; from then on, this part of the staircase was closed. Staircase 3 on the first floor was not greatly affected, and largely remained passable.

Figure 9 presents the smoke height variation of each evacuation exit on the first floor. Obviously, evacuation exits I and II, which are close to the ignition point, were greatly affected by the fire. Evacuation exit I was no longer passable since 86s; Evacuation exit II was passable, despite being seriously affected by fire; the other two exits were slightly affected by fire, and remained passable.

As shown in Figure 10, the temperature did not change significantly in classrooms and areas on the second floor, except the fire classroom. The average temperature variation was $5^{\circ} \mathrm{C}$. In the fire classroom (Figure 11 ), the smoke height increased linearly to the peak height in $10 \mathrm{~s}$, and then remained at that level. Meanwhile, the temperature in that room (Figure 12) surged up to above $200^{\circ} \mathrm{C}$.

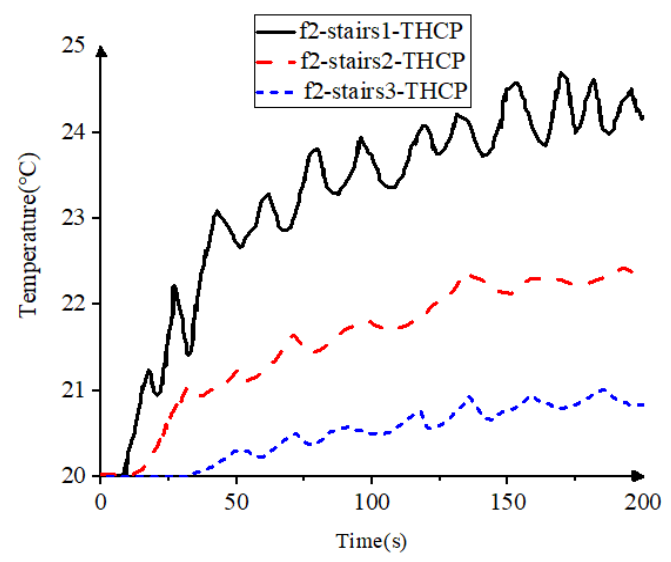

Figure 10. Temperature at each staircase on the second floor

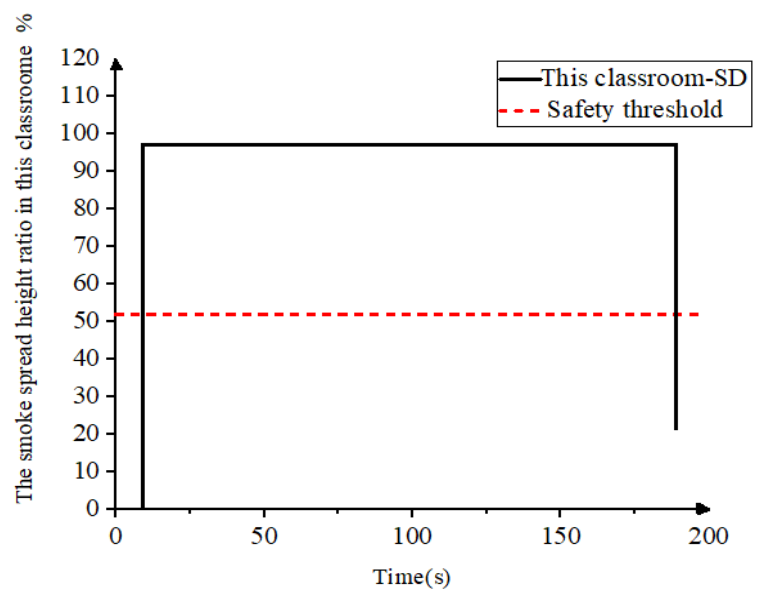

Figure 11. Smoke height in the fire classroom

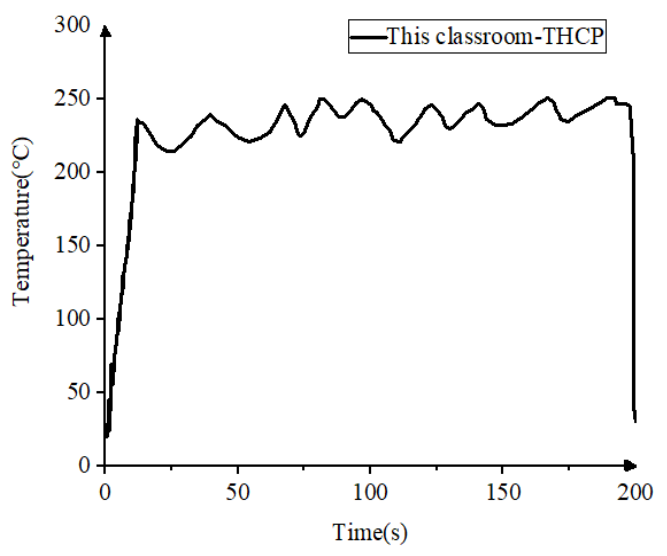

Figure 12. Temperature in the fire classroom 
Through the above fire analysis, the moment that each evacuation exit became impassable was obtained. Taking this moment as a constraint, the fire evacuation was simulated on Pathfinder software. The simulation results are recorded in Table 3. It can be seen that full evacuation of the personnel in the teaching building took 168 s under no fire, and 189 s under fire. The previous research [24] shows that a public place will enter the hazardous state within $5-8 \mathrm{~mm}$ after a fire break out. The simulated evacuation time under fire was only $189 \mathrm{~s}$, falling in the time range for safe evacuation.

Evacuation exit I, which lies close to the fire classroom, was closed since $86 \mathrm{~s}$. Therefore, the evacuation time through this exit plunged from $137 \mathrm{~s}$ under no fire to $84 \mathrm{~s}$ under fire. Evacuation exit II was not closed during the fire. As the main exit, the evacuation through this exit took a long time, due to the large flow. The evacuation time through this exit increased by $11 \mathrm{~s}$ after fire was taken into account. Evacuation exit III, far from the fire classroom, helps to divert some flow from evacuation exit II. After considering fire, it took $33 \mathrm{~s}$ more time to evacuate through this exit. Evacuation exit IV is the farthest one from the fire classroom. With a small flow, the evacuation time through this exit under fire was $7 \mathrm{~s}$ longer than that under no fire. To sum up, exit I is the only evacuation exit where the evacuation is faster under fire than under no fire.

Table 3. Evacuation time of each exit under fire

\begin{tabular}{cccc}
\hline Name & $\begin{array}{c}\text { Closing } \\
\text { moment } / \mathbf{s}\end{array}$ & $\begin{array}{c}\text { Evacuation time } \\
\text { under no fire /s }\end{array}$ & $\begin{array}{c}\text { Evacuation time } \\
\text { under fire /s }\end{array}$ \\
\hline Exit I & $86 \mathrm{~s}$ & 130 & 84 \\
Exit II & - & 168 & 179 \\
Exit III & - & 156 & 189 \\
Exit IV & - & 88 & 95 \\
\hline
\end{tabular}

\section{CONCLUSIONS}

In the new era, college administrators are faced with new challenges from fire safety. To ensure the fire safety of college buildings, this paper identifies the features and hazard sources of college building fires, and then establishes a fire model for a teaching building. The critical smoke height was determined based on the height of students in that college. Fire simulation shows that the smoke at staircases 1 and 2, which are close to the fire classroom, on the second floor reached the critical height at $63 \mathrm{~s}$ and $76 \mathrm{~s}$, respectively; despite a relatively long distance from the fire classroom, the smoke at staircase 3 on the second floor reached the critical height at $123 \mathrm{~s}$, making the staircase impassable. Among the four evacuation exits, exit I suffered the greatest from the fire, and became impassable since 86s. The other exits and stairways on the first floor were affected but still passable. Except the fire classroom. The average temperature variation on the second floor was $5^{\circ} \mathrm{C}$. After the fire broke out, the total evacuation time increased by $21 \mathrm{~s}$. Exit I is the only evacuation exit where the evacuation is faster under fire than under no fire. The research results provide a good reference for fire safety in similar college buildings. The future research will optimize the exit layout and prepare a suitable evacuation plan.

\section{ACKNOWLEDGMENT}

2019 Yiwu Industrial \& Commercial College Preparatory Research Project of National (Project No: YY-GJ-201903).

\section{REFERENCES}

[1] Wang, Z.N., Chen, J., Cheng, W.C., Arulrajah, A., Horpibulsuk, S. (2018). Investigation into the tempospatial distribution of recent fire hazards in China. Natural Hazards, 92(3): 1889-1907. https://doi.org/10.1007/s11069-018-3264-5

[2] Moinuddin, K.A.M., Sutherland, D. (2019). Modelling of tree fires and fires transitioning from the forest floor to the canopy with a physics-based model. Mathematics and Computers in Simulation, 175: 81-95.

[3] Chawinga, W.D., Majawa, F. (2018). An assessment of Mzuzu University Library after a fire disaster. African Journal of Library, Archives \& Information Science, 28(2): 183-194.

[4] Gao, R., Li, A., Hao, X., Lei, W., Zhao, Y., Deng, B. (2012). Fire-induced smoke control via hybrid ventilation in a huge transit terminal subway station. Energy and Buildings, 45: 280-289. https://doi.org/10.1016/j.enbuild.2011.11.018

[5] Ayala, P., Cantizano, A., Gutiérrez-Montes, C., Rein, G. (2013). Influence of atrium roof geometries on the numerical predictions of fire tests under natural ventilation conditions. Energy and Buildings, 65: 382390. https://doi.org/10.1016/j.enbuild.2013.06.010

[6] Tan, L., Hu, M., Lin, H. (2015). Agent-based simulation of building evacuation: Combining human behavior with predictable spatial accessibility in a fire emergency. Information Sciences, 295: 53-66. https://doi.org/10.1016/j.ins.2014.09.029

[7] Wang, Z.L., Hua, M., Xu, D.Y., Pan, X.H. (2014). Simulation research on human evacuation in subway with a single-point fire scenario. Procedia Engineering, 84: 595-602. https://doi.org/10.1016/j.proeng.2014.10.472

[8] Alonso, A., Lázaro, M., Lázaro, P., Lázaro, D., Alvear, D. (2020). Assessing the influence of the input variables employed by fire dynamics simulator (FDS) software to model numerically solid-phase pyrolysis of cardboard. Journal of Thermal Analysis and Calorimetry, 140(1): 263-273. https://doi.org/10.1007/s10973-019-08804-6

[9] Liang, T., Liu, J., Tao, P. (2019). The implementation of the numerical simulation by utilization of pyrosim on the rectification of the hazard of fires. In Proceedings of the 11th International Conference on Computer Modeling and Simulation, $\quad$ pp. 31-35. https://doi.org/10.1145/3307363.3307397

[10] Khandoker, M.A.R., Mou, R.J., Muntaha, M.A., Rahman, M. A. (2018). Numerical simulation of fire in a multistoried ready-made garments factory using PyroSim, AIP Conference Proceedings. AIP Publishing LLC, (1): 050026. https://doi.org/10.1063/1.5044362

[11] Chen, F., Chien, S. W., Lee, Y. P., Lin, C. F., Sie, H. R. (2013). The integrated strategies for fire safety of long road tunnels in Taiwan. Procedia Engineering, 62: 36-45. https://doi.org/10.1016/j.proeng.2013.08.042

[12] Cui, T.J., Ma, Y.D. (2013). FDS-based fire simulation and evacuation plan for subway station in course of construction. Journal of Natural Disasters, 22(6): 178184.

[13] Meng, N., Hu, L., Wu, L., Yang, L., Zhu, S., Chen, L., Tang, W. (2014). Numerical study on the optimization of smoke ventilation mode at the conjunction area between tunnel track and platform in emergency of a train fire at 
subway station. Tunnelling and Underground Space Technology, 40: 151-159. https://doi.org/10.1016/j.tust.2013.09.014

[14] Oztekin, E.S. (2014). Heat and mass transfer due to a small-fire in an aircraft cargo compartment. International Journal of Heat and Mass Transfer, 73: 562-573. https://doi.org/10.1016/j.ijheatmasstransfer.2014.02.019

[15] Liang, J.H., Li, X., Lin, J.H., Li, L., Liu, J.Z. (2014). Analyses of EMU fire based on pyrosim. Journal of Chongqing University of Technology (Natural Science), 28(10): 35-37.

[16] Chen, J.W., Guan, Z.J., Kang, Q.S. (2015). Simulation Study on Library Evacuation Based on Pathfinder. China Academic Electronic Publishing House, 16: 170-179.

[17] Fang, T., Yu, J., Wang, J. (2012). Study of staircase design effects on evacuation in architectural plane design. Journal of Applied Fire Science, 22(1): 69-80. https://doi.org/10.2190/AF.22.1.e

[18] Fang, Z., Lo, S.M. (2002). On quantitative study of evacuation in buildings. Engineering Journal of Wuhan University, 35(2):

72-75. https://doi.org/CNKI:SUN:WSDD.0.2002-02-017

[19] Glasa, J., Valasek, L., Weisenpacher, P., Halada, L. (2013). Cinema fire modelling by FDS. Journal of Physics: Conference Series. IOP Publishing, 410(1):
012013. $6596 / 410 / 1 / 012013$

[20] Huo, F., Song, W., Chen, L., Liu, C., Liew, K.M. (2016). Experimental study on characteristics of pedestrian evacuation on stairs in a high-rise building. Safety Science, $\quad 86: \quad 165-173$. https://doi.org/10.1016/j.ssci.2016.02.025

[21] Chi, J. H. (2014). Using FDS program and an evacuation test to develop hotel fire safety strategy. Journal of the Chinese Institute of Engineers, 37(3): 288-299. https://doi.org/10.1111/j.1556-4029.2012.02297.x

[22] Long, X., Zhang, X., Lou, B. (2017). Numerical simulation of dormitory building fire and personnel escape based on Pyrosim and Pathfinder. Journal of the Chinese Institute of Engineers, 40(3): 257-266. https://doi.org/10.1080/02533839.2017.1300072

[23] Rahouti, A., Datoussaïd, S., Descamps, T. (2018). Safety assessment of a high-rise dormitory in case of fire. International Journal of Disaster Resilience in the Built Environment, $9(1)$ : $84-95$. https://doi.org/10.1108/ijdrbe-10-2016-0039

[24] Li, Q., Cui, X.H., Chen, J. (2011). Simulation and application of evacuation strategies for large public places. Beijing Meteorological Press. 